\title{
Preventive effects of metallothionein against DNA and lipid metabolic damages in dyslipidemic mice under repeated mild stress
}

\author{
Minoru Higashimoto ${ }^{\mathrm{a}, \mathrm{b}}$, Naohiro Isoyama ${ }^{\mathrm{a}}$, Satoshi Ishibashi ${ }^{\mathrm{a}}$, Naoko Ogawa $^{\mathrm{c}}$ \\ Masufumi Takiguchi ${ }^{\mathrm{a}, \mathrm{d}}$, Shinya Suzuki ${ }^{\mathrm{a}}$, Yoshinari Ohnishi ${ }^{\mathrm{e}}$, and Masao Sato ${ }^{\mathrm{a}}$ \\ ${ }^{a}$ Faculty of Pharmaceutical Sciences, Tokushima Bunri University, Tokushima, Japan, ${ }^{\mathrm{b}}$ AWA Laboratory \\ of Health-Food Drinks, Tokushima, Japan, 'Faculty of Human Life Sciences, Tokushima Bunri Uni- \\ versity, Tokushima, Japan, 'Faculty of Pharmaceutical Sciences, Hiroshima International University, \\ Hiroshima, Japan, and ${ }^{\circ}$ Graduate School of Medicine, the University of Tokushima, Tokushima, Japan
}

\begin{abstract}
The effects of repeated mild stress on DNA and lipid metabolic damages in multiple organs of dyslipidemic mice, and the preventive role of metallothionein (MT) were investigated. Female adult wild-type and MT-null mice fed high-fat diet (HFD) or standard diet (STD) were repeatedly subjected to fasting or restraint for three weeks. The liver, pancreas, spleen, bone marrow and serum samples were taken for evaluating DNA damage, MT, glutathione (GSH), corticosterone, carnitine and adiponectin. Body weights of restraint groups were reduced with the intensity of stress increased, even if the energy intakes were higher than those of STD group. Hepatic GSH levels were reduced in HFD control group and were further reduced in stress groups, especially in restraint groups, while the hepatic MT and serum corticosterone levels were increased in concert with the intensity of stress. Cellular DNA damages were generally increased by the restraint stress, especially in MT-null mice. Hepatic carnitine levels of MT-null mice were markedly lower than those of wild-type mice. The data suggest that MT plays a preventive role by acting as an antioxidant in corporation with GSH decreased by repeated stress and that MT may be an essential factor for inducing carnitine under the stress. J. Med. Invest. 60 : 240-248, August, 2013
\end{abstract}

Keywords : metallothionein, repeated mild stress, DNA damage, dyslipidemia

\section{INTRODUCTION}

The presence of excess reactive oxygen species (ROS) can cause cellular damage via oxidation of

Received for publication March 22, 2013 ; accepted May 6, 2013.

Address correspondence and reprint requests to Minoru Higashimoto, AWA Laboratory of Health-Food Drinks, 89 Kitabara, Awa-cho, Awa-shi, Tokushima 771-1703, Japan and E-mail : higashiyh@ybb.ne.jp. biomolecules, including DNA, proteins and polyunsaturated fatty acids, causing a variety of diseases such as cancer, Parkinson's disease, and cardiovascular disease $(1,2)$. It has been shown that mental and physiological stresses induce excess ROS and worsen lifestyle-related diseases (3-5). To reduce the formation of excess ROS is important for preventing the development of diseases.

The authors have been studying the metallothionein (MT) synthesis induced by a variety of 
stresses, and the antioxidant effect of MT (6-10). MT is known as a cysteine-rich, low molecular weight and metal-binding protein (11) and has several interesting biological effects including detoxification of heavy metals, regulation of the homeostasis of essential metals, and antioxidant effects against reactive oxygen species (12-15). We previously reported that food-induced dyslipidemia in mice could be accelerated by repeated fasting, but could be suppressed by repeated restraint, and that the DNA damage in cells of various organs was increased by the repeated stress, especially in MTnull mice (9). Glutathione (GSH) is the most abundant antioxidant in the liver, and plays most significant role against toxicity of ROS including superoxide, hydrogen peroxide and hydroxyl radicals. Among ROS, hydroxyl radicals have the strongest toxicity. Although GSH concentration is greater than those of other antioxidants in the liver, MT has the strongest affinity with the hydroxyl radicals (16). MT may play a preventive role against ROS in cooperation with or instead of GSH $(12,17,18)$. In our previous study, however, we could not explore the relationship between GSH and MT under repeated stress, due to the 12 -h fasting before sacrifice to determine serum cholesterol levels (9). Therefore, in the present study, we tried to elucidate the pre-sacrifice defense systems by limiting the fasting period before sacrifice to 2 hours. We determined here not only MT and GSH levels but also corticosterone level which is known as an indicator of biological stress (19). In the previous paper, we also reported that the body weight of restraint mice fed high-fat diet (HFD) was markedly decreased although the total energy intake was higher than that of control mice fed standard diet (STD), suggesting that the energy metabolism system may be changed by the repeated restraint stress. In the present study, we investigated two factors, carnitine and adiponectin, in the energy metabolic system. Carnitine is an amino acid derivative which is essential for the incorporation of long-chain fatty acid into mitochondria (20-22). Adiponectin is an anti-diabetic adipokine which is specifically and abundantly produced in the white adipose tissue (23-25). We describe here the results of investigation concerning to the effects of repeated mild stress on the biological defense systems and lipid metabolic systems in mice fed dyslipidemia-inducing HFD.

\section{EXPERIMENTAL METHODS}

\section{Animal treatments}

Female adult 129/Sv wild-type and MT-null mice (Jackson Laboratory, USA ; 21-24 $\mathrm{g}$ in body weight) were each divided into six groups. The mice assigned to the stress groups were fed HFD for 4 weeks and were subjected to fasting for 24 hours from 20:00 on every other day, three times per week (F24), or to restraint with tube for $15 \mathrm{~min}$ (R15), 30 min (R30) or 60 min (R60) daily on weekdays, in weeks 2 to 4 of the 4 -week study period as shown in the previous paper (9). Control mice were fed STD (C1) or HFD (C2) for 4 weeks without being subjected to any stress. The HFD (Crea Japan, Osaka, Japan), specially produced for our laboratory, was based on the AIN 76 diet (26), containing $12 \%$ corn oil, $13 \%$ beef tallow, $1 \%$ cholesterol, $0.2 \%$ cholic acid, and $418.2 \mathrm{kcal} / 100 \mathrm{~g}$. The STD (CE-2) containing $4.4 \%$ fat and $342.2 \mathrm{kcal} / 100 \mathrm{~g}$ was purchased from Crea Japan. These solid-type diets were weighed and fed adequately. Total energy intakes were calculated as the sum of diet eaten by each treatment groups during the experiment. Cages of the animals were cleaned regularly during the fasting period to prevent coprophagy. Restraint was performed using a handmade restraint device, a 50 -ml plastic centrifuging tube modified for this experiment, as shown in Fig. 1. It has twelve $3-\mathrm{mm}$ diameter holes for sweating, and one hole for tail-protecting, and four holes fitted two steel rings for the animal's habitual teeth grinding and for protecting the holes for animal's breathing. Volume of centrifuging tube was changed in response to the size of

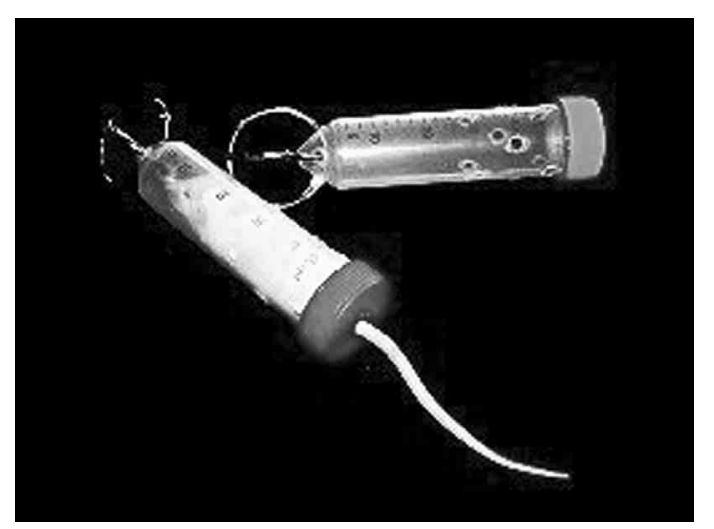

Fig. 1 Handmade restraint device.

A $50 \mathrm{ml}$-plastic centrifuging tube has twelve 3 - $\mathrm{mm}$ diameter holes for sweating, and one hole for tail-protecting, and four holes fitted two steel rings for the animal's habitual teeth grinding and for protecting the holes for animal's breathing. 
the animal. At the end of the treatment period, mice loaded with stress were fed HFD for approximately one day, and all the animals were fasted for 2 hours before they were sacrificed. All experimental procedures were approved by the Animal Care and Use Committee of Tokushima Bunri University and conformed to the guidelines established by the Japanese Ministry of Education, Culture, Sports, Science and Technology.

\section{Sample preparation}

At the end of the 4-week study period, blood samples were collected from the supraorbital vein of the animals under pentobarbital anesthesia. Then, the liver, pancreas and spleen were quickly removed from each animal, weighed and placed on ice. The bone marrow cells were collected from the femur and eluted with a phosphate buffered saline.

\section{Comet assay}

Aliquots of mouse organs (liver, pancreas and spleen) were homogenized. The homogenates and bone marrow eluate were subjected to the comet assay $(27,28)$ using the CometAssay and Silver Staining Kits (Trevigen, Gaitherburg, MD, USA) and SYBR Gold (Invitrogen, Eugene, OR, USA). The comet images obtained using an optical or a fluorescence microscope equipped with a digital camera were analyzed and were scored using a comet analysis software (CometAnalyzer, Youworks, Tokyo, Japan). The DNA damage was expressed as a ratio of the total comet length to the diameter of the head DNA from 100 cells of each organ.

\section{Protocols for other assays}

Liver and serum samples were stored at $-35^{\circ} \mathrm{C}$ and $4^{\circ} \mathrm{C}$ until assay, respectively. Total GSH levels in the liver were determined with the GSH Quantification Kit (Dojindo, Kumamoto, Japan). Hepatic MT concentrations of wild-type mice were determined by the Cd-heme method (29). Serum corticosterone, adiponectin and hepatic total carnitine levels were determined with the respective quantification kits (Assay Designs, Ann Arbor, MI, USA; Otsuka Pharmaceutical, Tokyo, Japan ; and KAINOS Laboratories, Tokyo, Japan).

\section{Statistical analysis}

Data are presented as mean \pm SEM. Differences in means were analyzed using unpaired $t$-test with InStat 2.0 (GraphPad Software Inc.). Statistical significance was defined as $p<0.05$.

\section{RESULTS}

\section{Body weight change}

Body weights of wild-type mice of HFD control (C2) and 24-h fasted group (F24) were similarly increased and were higher than those of mice fed STD (C1) as shown in Fig. 2A. On the other hand, the increases in body weight of the restraint groups (R15, R30, R60) were clearly reduced in proportion to the intensity of stresses as shown in Fig. 2A. Similar tendencies were seen in MT-null mice, although their weight gains were slightly greater than those of wild-type mice as shown in Fig. 2B.
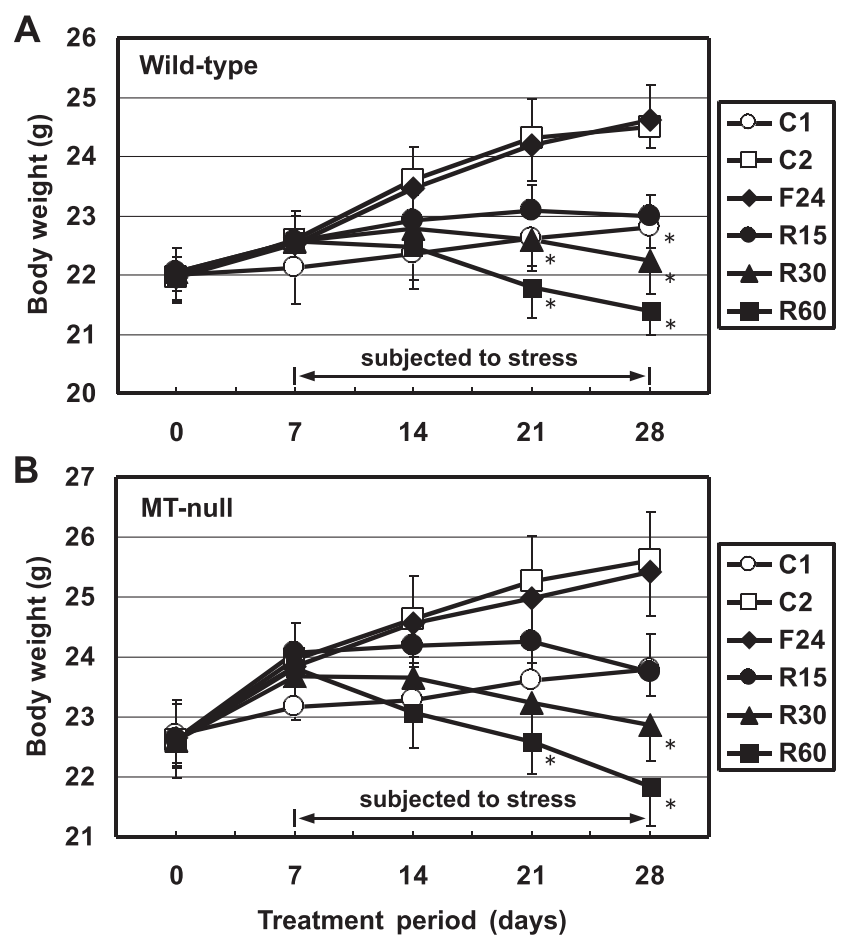

Fig. 2 Change in body weight in (A) wild-type and (B) MTnull mice fed standard diet or high-fat diet with or without fasting or restraint stress.

$\mathrm{C} 1$, standard diet control ; C2, high-fat diet control ; F24, high-fat diet plus fasting for $24 \mathrm{~h}$; R15, R30, and R60, high-fat diet plus restraint for 15, 30, and $60 \mathrm{~min}$, respectively. Data are presented as mean $\pm \mathrm{SEM}, \mathrm{n}=10{ }^{*} p<0.05$ vs. corresponding $\mathrm{C} 2$ group.

\section{Total energy intake}

Total energy intakes in the wild-type and MT-null mice groups were expressed as the percentage to the total energy intake in the corresponding STD groups (Fig. 3). Relative energy intake was higher for all groups fed HFD than that for the corresponding STD group as shown in Figs. 3A and 3B. Both in wild-type and MT-null mice, total energy intake of 24-h fasting groups was similar to that of the corresponding HFD control group, whereas total energy intake of three restraint groups was slightly 
reduced compared with that of the corresponding HFD control group. In general, the fat-energy intakes of all HFD groups were much higher than that of the corresponding STD group.

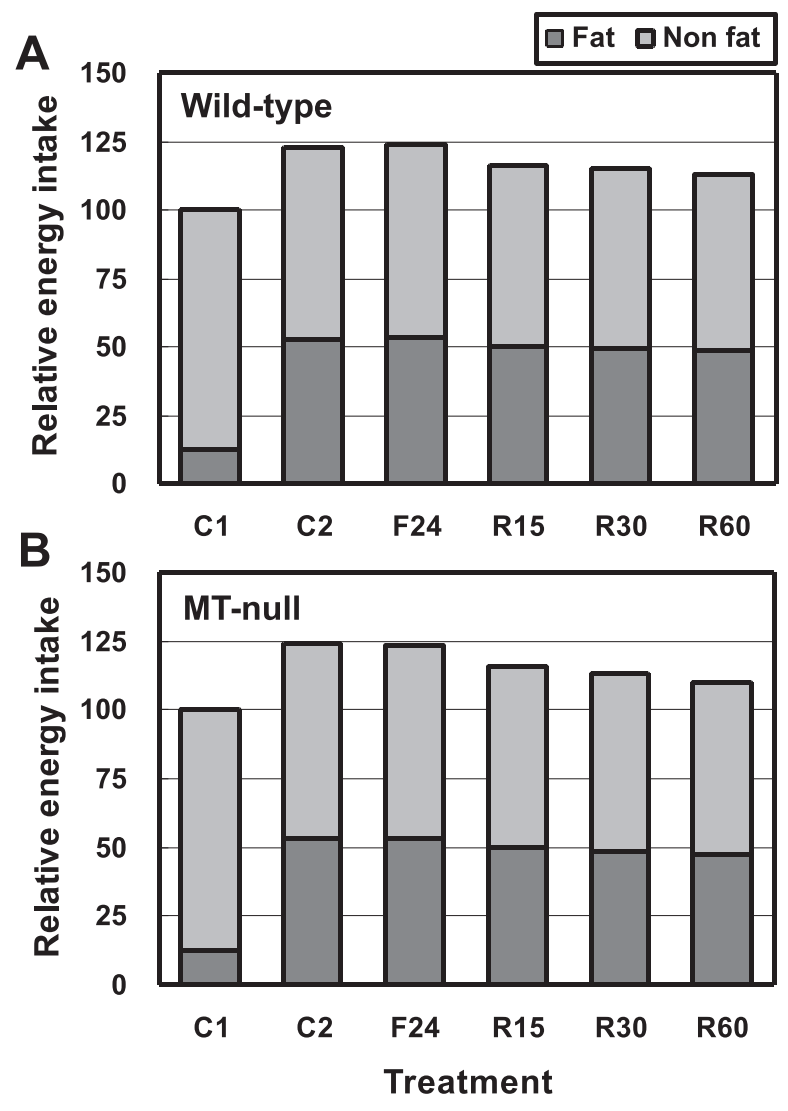

Fig. 3 Relative total intake of nonfat and fat energy in (A) wildtype and (B) MT-null mice fed standard diet or high-fat diet with or without fasting or restraint stress.

$\mathrm{C} 1$, standard diet control ; 2 , high-fat diet control ; F24, highfat diet plus fasting for $24 \mathrm{~h}$; R15, R30, and R60, high-fat diet plus restraint for 15,30 , and $60 \mathrm{~min}$, respectively.

\section{Liver weight}

In wild-type mice, the liver weight of HFD control group was significantly higher than that of STD control group, and that of 24 -h fasting group was extremely higher (ca. 1.9 fold) than that of HFD control group as shown in Fig. 4. On the other hand, the liver weights of restraint groups were slightly lower than that of the HFD control group. Similar tendency was observed in the liver weights of MTnull mice. There were no significant differences in the liver weights between wild-type mice and MTnull mice in the corresponding treatment group, although the weights of MT-null mice tended to be a little higher than those of wild-type mice.

As was previously reported (9), the other organs, pancreas and spleen, excised from the mice showed no distinct differences both in weight and shape among the treatment groups.

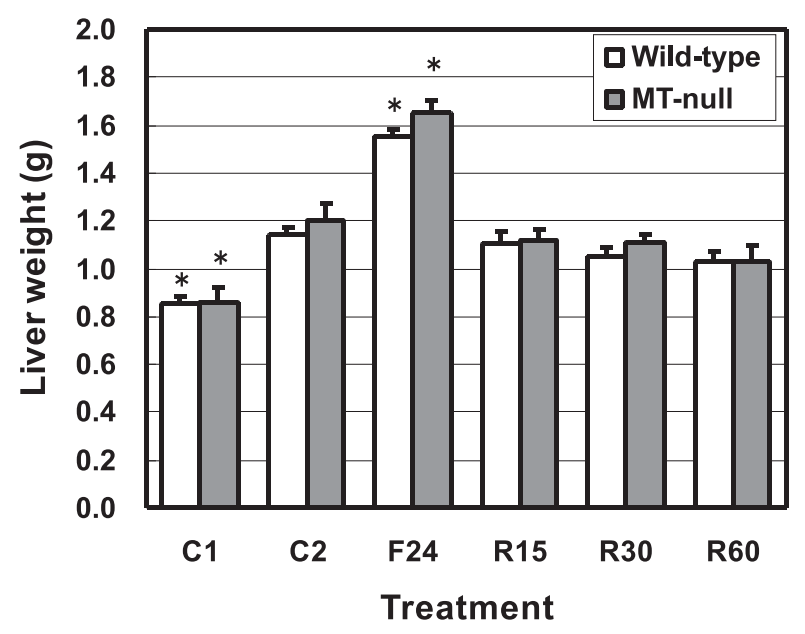

Fig. 4 Liver weight of wild-type and MT-null mice fed standard diet or high-fat diet with or without fasting or restraint stress. $\mathrm{C} 1$, standard diet control ; $\mathrm{C} 2$, high-fat diet control ; F24, high-fat diet plus fasting for $24 \mathrm{~h}$; R15, R30, and R60, high-fat diet plus restraint for 15,30 , and $60 \mathrm{~min}$, respectively. Data are presented as mean \pm SEM, $\mathrm{n}=10$. ${ }^{*} p<0.05$ vs. corresponding $\mathrm{C} 2$ group.

\section{Hepatic concentrations of GSH and MT}

Total GSH levels in the liver of mice were shown in Fig. 5. In the wild-type mice, the GSH level of HFD control group was significantly decreased compared to that of STD control group, and the GSH levels were gradually reduced as the length of restraint time increased. Similar tendency was observed in the MT-null mice, and the GSH levels

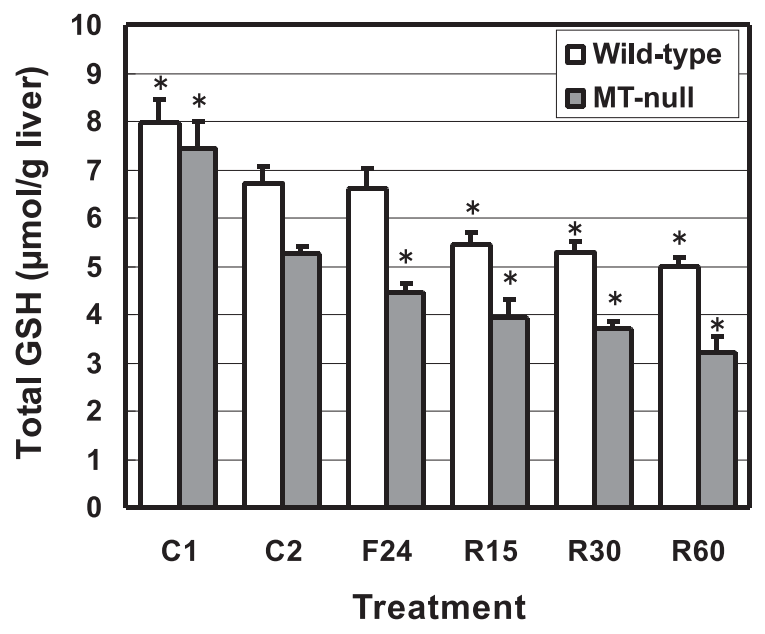

Fig. 5 Hepatic total glutathione levels in wild-type and MT-null mice fed standard diet or high-fat diet with or without fasting or restraint stress.

$\mathrm{C} 1$, standard diet control ; C2, high-fat diet control ; F24, high-fat diet plus fasting for $24 \mathrm{~h}$; R15, R30, and R60, high-fat diet plus restraint for 15,30 , and $60 \mathrm{~min}$, respectively. Data are presented as mean $\pm \mathrm{SEM}, \mathrm{n}=10$. $* p<0.05$ vs. corresponding $\mathrm{C} 2$ group. 
were clearly lower than those of wild-type mice.

On the other hand, MT levels in the liver of wild-type mice was markedly increased (ca. 1.6 fold of $\mathrm{C} 1$ ) by 24-h fasting, and were increased as the length of restraint time increased, as shown in Fig. 6.

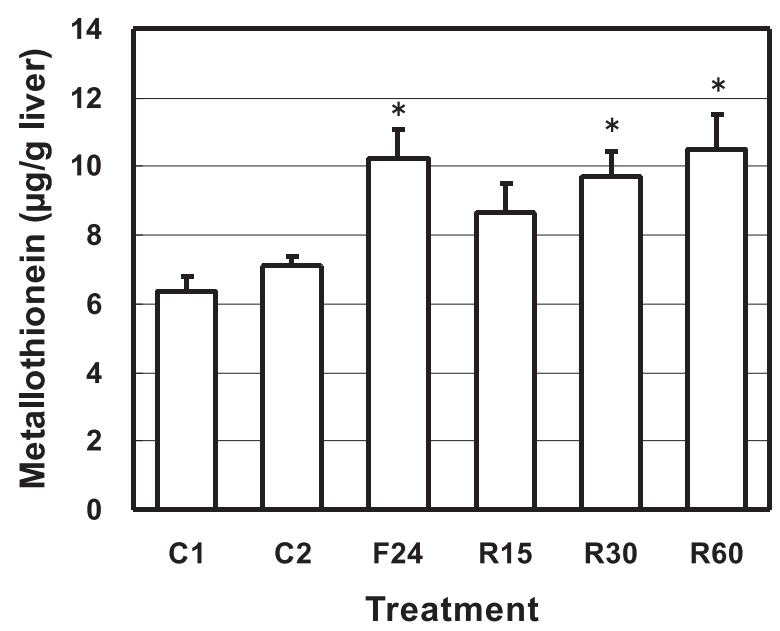

Fig. 6 Hepatic metallothionein levels in wild-type mice fed standard diet or high-fat diet with or without fasting or restraint stress.

$\mathrm{C} 1$, standard diet control ; 2 , high-fat diet control ; F24, high-fat diet plus fasting for $24 \mathrm{~h}$; R15, R30, and R60, high-fat diet plus restraint for 15,30 , and $60 \mathrm{~min}$, respectively. Data are presented as mean $\pm \mathrm{SEM}, \mathrm{n}=10 . * p<0.05$ vs. $\mathrm{C} 2$ group.

\section{Serum corticosterone concentration}

Corticosterones in the serum of wild-type mice were markedly increased in the restraint groups compared with STD- and HFD-control groups as shown in Fig. 7. Similar tendency was observed in the serum corticosterone levels of MT-null mice, which were slightly higher than those of wild-type mice in general.

\section{DNA damage in the cells of mouse organs}

DNA damages in the liver, pancreas, spleen and bone marrow cells of wild-type and MT-null mice were shown in Fig. 8. The increase of DNA damage was generally seen in the cells of mice in restraint groups, but not so clear in the cells of fasted mice. Specifically, in the MT-null mice, the DNA damages in almost all organ cells of restraint mice were markedly increased as shown in the figures A-D. On the other hand, in wild-type mice, DNA damages were significantly increased in the pancreas and bone marrow of the 30-min restraint group, and in the liver, spleen and bone marrow of the 60 -min restraint group. In all restraint groups, the levels of

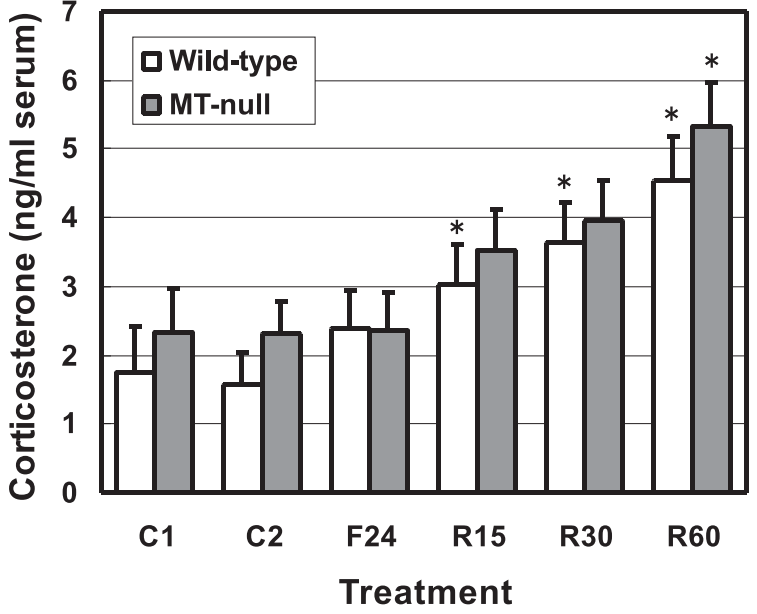

Fig. 7 Serum corticosterone levels in wild-type and MT-null mice fed standard diet or high-fat diet with or without fasting or restraint stress.

$\mathrm{C} 1$, standard diet control ; $\mathrm{C} 2$, high-fat diet control ; F24, high-fat diet plus fasting for $24 \mathrm{~h}$; R15, R30, and R60, high-fat diet plus restraint for 15, 30, and $60 \mathrm{~min}$, respectively. Data are presented as mean $\pm \mathrm{SEM}, \mathrm{n}=10$. $* p<0.05$ vs. corresponding $\mathrm{C} 2$ group.

DNA damage in MT-null mice were clearly greater than those in wild-type mice. Significant increases in DNA damage by the HFD and 24-h fasting stress were not observed in the present study.

\section{Changes in hepatic carnitine and serum adiponectin levels}

In the wild-type mice, hepatic total carnitine levels were not so affected by the stresses of fasting and restraint in the present study, as shown in Fig. 9. On the other hand, in the MT-null mice, the carnitine levels were markedly decreased compared with those in the wild-type mice. In the restraint mice, the carnitine levels were particularly decreased with the increase of stress intensity compared with those in STD control mice.

Serum adiponectin level was significantly decreased in HFD control group compared with STD control group and was further decreased in 24-h fasting group as shown in Fig. 10. On the other hand, the adiponectin levels in restraint groups were increased up to almost the same as that in STD control group. It is suggested that the adiponectin reduction by a factor(s) contained in HFD may be inhibited by the repeated mild restraint stress. No differences in the serum adiponectin level were observed between the two types of mice in the present study. 

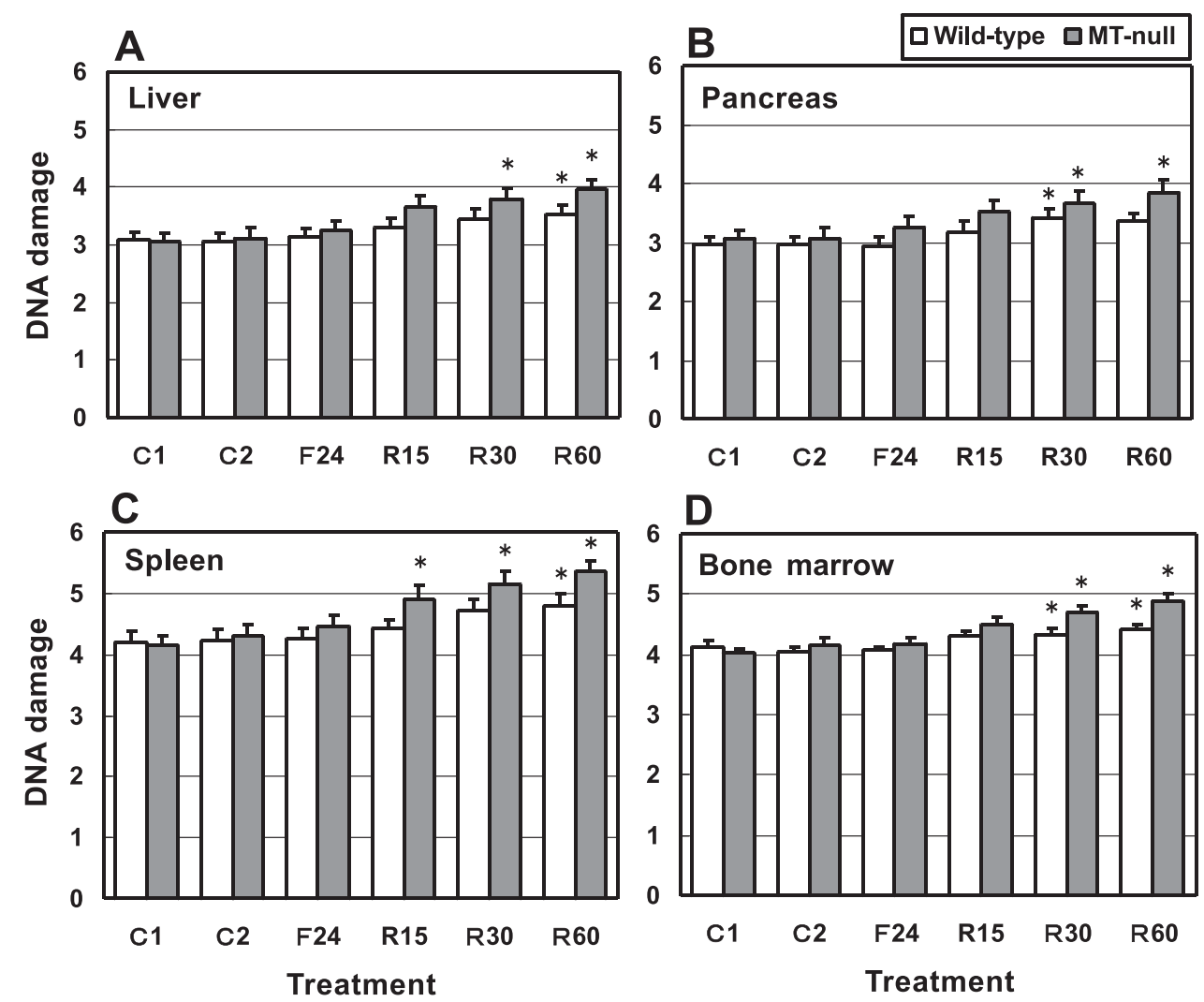

Fig. 8 DNA damage in the (A) liver, (B) pancreas, (C) spleen, and (D) bone marrow cells of wild-type and MT-null mice fed standard diet or high-fat diet with or without fasting or restraint stress.

$\mathrm{C} 1$, standard diet control ; 2 , high-fat diet control ; F24, high-fat diet plus fasting for $24 \mathrm{~h}$; R15, R30, and R60, high-fat diet plus restraint for 15, 30, and $60 \mathrm{~min}$, respectively. Data are presented as mean $\pm \mathrm{SEM}, \mathrm{n}=10{ }^{*} p<0.05$ vs. corresponding $\mathrm{C} 2$ group.

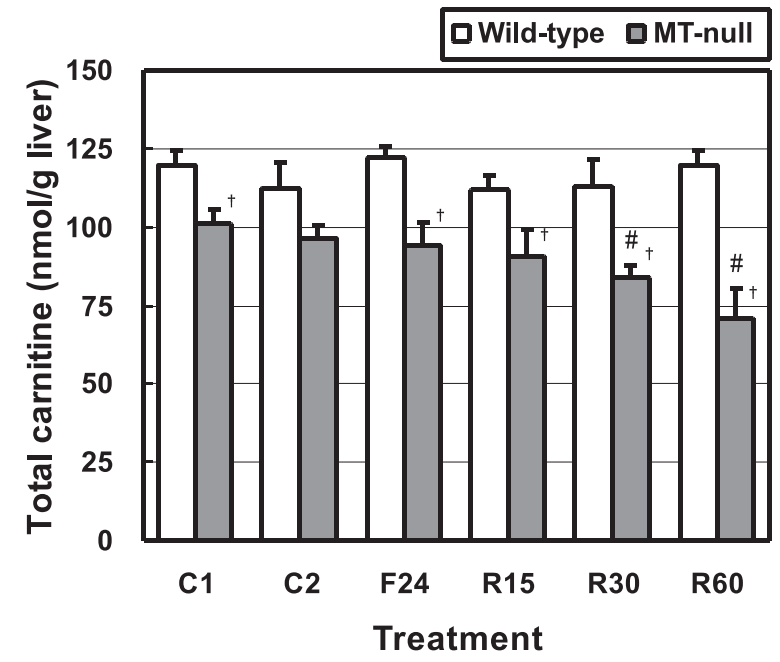

Fig. 9 Hepatic total carnitine levels in wild-type and MT-null mice fed standard diet or high-fat diet with or without fasting or restraint stress.

$\mathrm{C} 1$, standard diet control ; 2 , high-fat diet control ; F24, high-fat diet plus fasting for $24 \mathrm{~h}$; R15, R30, and R60, high-fat diet plus restraint for 15,30 , and $60 \mathrm{~min}$, respectively. Data are presented as mean \pm SEM, $\mathrm{n}=10 .{ }^{*} p<0.05$ vs. corresponding $\mathrm{C} 2$ group. ${ }^{\dagger} p<0.05$ vs. corresponding wild-type mice.

\section{DISCUSSION}

It has been shown that GSH is probably the most

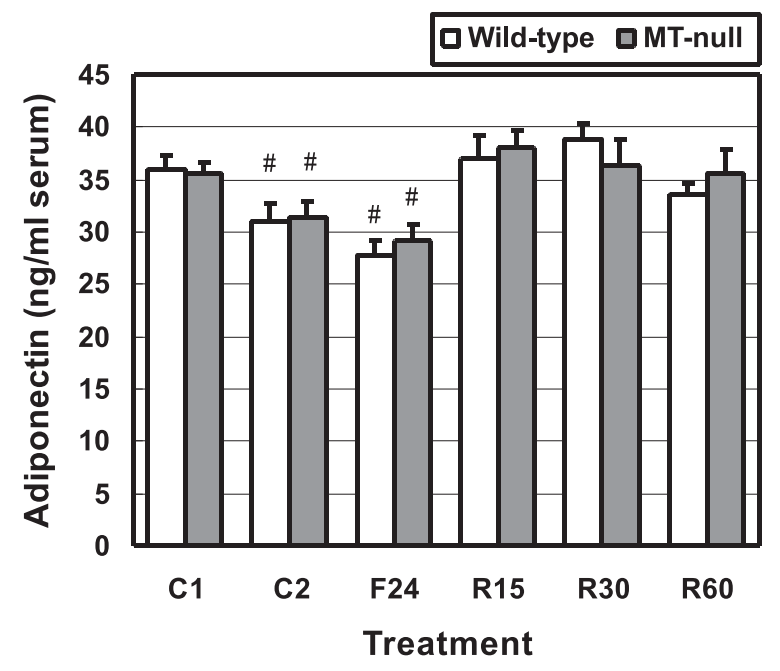

Fig. 10 Serum adiponectin levels in wild-type and MT-null mice fed standard diet or high-fat diet with or without fasting or restraint stress.

$\mathrm{C} 1$, standard diet control ; C2, high-fat diet control ; F24, high-fat diet plus fasting for $24 \mathrm{~h}$; R15, R30, and R60, high-fat diet plus restraint for 15,30 , and $60 \mathrm{~min}$, respectively. Data are presented as mean $\pm \mathrm{SEM}, \mathrm{n}=10$. ${ }^{*} p<0.05$ vs. corresponding $\mathrm{C} 1$ group.

important cellular antioxidant $(17,30)$. MT may act as a secondary antioxidant in a cellar protection system in the absence of GSH $(18,31)$. In the previous 
study (9), we failed to observe the exact accumulated effect by repeated stress on the primary biological defense systems involving GSH and MT because mice were fasted for 12 hours before sacrifice to determine serum cholesterol. In the present study, however, we could investigate the defense systems in $129 / \mathrm{Sv}$ wild-type and MT-null mice fed standard diet or high-fat diet with or without fasting or restraint stress, by limiting the fasting time before sacrifice to 2 hours. It was clearly shown that the total amount of GSH stored in the liver was gradually decreased with the intensity of stress increased both in the wild-type and MT-null mice (Fig. 5), and that hepatic MT levels of wild-type mice were increased in response to the decline of GSH, suggesting that MT plays a preventive role as an antioxidant in corporation with decreased GSH which is a primary radical scavenger for DNA and lipid metabolic damages in murine organs induced by repeated mild stress $(12,17,18)$. If MT has more potent antioxidant effect than GSH against the hydroxyl radicals which are known as highly strong reactive oxygen species interacting with DNA, it may act not only as a supplementary radical scavenger but also as an extraordinarily efficient hydroxyl radical scavenger, as stated by Thornalley and Vašák (16). The specific induction (1.6 fold) of MT in the liver of wild-type mice subjected to 24-h fasting (Fig. 6) must be a specific adaptation of liver tissue in response to the repeated severe stress. In these animals, the MT levels in the hypertrophic liver (1.9 fold in weight, Fig. 4) were increased approximately three times compared with those of STD mice. Serum corticosterone levels were markedly increased in the restraint groups compared with that of the corresponding control group as shown in Fig. 7, demonstrating that stresses were loaded well in this study.

Both in wild-type and MT-null mice, the body weight gains of mice subjected to mild restraint for $60 \mathrm{~min}$ /day or less and fed HFD, were markedly suppressed compared with those of mice fed STD (Fig. 2), even if the total energy intakes were higher than those of control mice fed STD (Fig. 3), suggesting that the energy metabolism system may be changed by the repeated restraint stress as previously reported (9). Then, we investigated two factors involved in the energy metabolic system, carnitine and adiponectin. It was found that hepatic total carnitine levels in MT-null mice were generally decreased compared with those in wild-type mice and were particularly decreased with the increase in intensity of restraint compared with those in STD mice as shown in Fig. 9. Carnitine is known not only as an essential factor for biological lipid metabolism, but also as an antioxidant against biological reactive oxygen species $(20-22,32)$. Present data suggest that the hepatic carnitine levels were reduced by HFD, and that the reduction might have been enhanced by stresses and further accelerated additionally by the lack of MT in MT-null mice. The results indicate that MT may be one of the essential factors for the induction of carnitine and that the reduction of carnitine induced in MT-null mice must be one of the reasons why MT-null mice tend to be obese (33). The reduction of carnitine with the increase in intensity of restraint in MT-null mice suggests the possibility that, even in wild-type mice, obesity may be induced via reduction in carnitine level under the overlap of loading of stress and lack of MT. Although serum adiponectin levels were significantly decreased in HFD control mice compared with STD control mice and were further decreased in 24-h fasted mice, adiponectin levels in restraint mice were almost the same as those in STD control mice. The decreases in serum adiponectin in $\mathrm{C} 2$ and F24 groups as shown in Fig. 10 might be reflects the increase in body and liver weights mainly due to their fat gain $(23-25,34)$ as shown in Figs. 2 and 4. MT did not affect the induction of serum adiponectin in the present experiment. We observed here two factors, carnitine and adiponectin, concerning lipid metabolism. Further studies are needed for other factors such as triglyceride, cholesterol, and enzymes to clarify the effect of stress on lipid metabolism.

In the present study, we investigated the DNA damage in the cells of four murine organs susceptible to the influence of stress, using mild restraint stress for 15-60 min/day. While some benefits of stress including suppression of body weight gain were observed, mild DNA damages were also detected in the cells of murine organs. Mild and beneficial stress is known to activate brain and promote our health, especially in the elderly $(1,35)$. It has been suggested that some antioxidative foods (2, $36,37)$ may be able to protect the unavoidable mild DNA damage by utilizing the hormetic effect of mild (beneficial) stress $(5,38)$ as observed in the present study.

MT can be induced by zinc, an essential mineral contained in many foods such as fish and shellfish, meat, nuts and seeds, and so on. Daily intake of zinc from ordinary foods may be effective not only for 
maintaining the physiological functions of the body such as fertility and immunity $(39,40)$ but also for inducing MT in the body $(41,42)$. In addition, many antioxidative foods containing many kinds of antioxidant components that protect mild DNA damages induced by moderate stresses should be extensively studied.

\section{CONFLICT OF INTEREST}

None of the authors have any conflicts of interest to declare.

\section{ACKNOWLEDGEMENT}

This work was supported in part by a Grant-inAid for General Scientific Research from the Ministry of Education, Culture, Sports, Sciences and Technology of Japan. We wish to thank Drs. T. T. Tsuda and A. Umehara (Tokushima Bunri University, Tokushima, Japan) for their support on carnitine analysis.

\section{REFERENCES}

1. Olinski R, Siomek A, Rozalski R, Gackowski D, Foksinski M, Guz J, Dziaman T, Szpila A, Tudek B : Oxidative damage to DNA and antioxidant status in aging and age-related diseases. Acta Biochim Polonica 54 : 11-26, 2007

2. Palafox-Carlos H, Ayala-Zavala JF, GonzálezAguilar GA: The role of dietary fiber in the bioaccessibility and bioavailability of fruit and vegetable antioxidants. J Food Sci 76 : R6-R15, 2011

3. Fukuda S, Morimoto K : Lifestyle, stress and cortisol response : Review I, mental stress. Environ Health Prev Med 6 : 9-14, 2001

4. Fukuda S, Morimoto K : Lifestyle, stress and cortisol response : Review II, lifestyle. Environ Health Prev Med 6 : 15-21, 2001

5. Meydani M, Hasan ST: Dietary polyphenols and obesity. Nutrients $2: 737-751,2010$

6. Kondoh $M$, Tsukada $M$, Kuronaga $M$, Higashimoto M, Takiguchi M, Himeno S, Watanabe Y, Sato M : Induction of hepatic metallothionein synthesis by endoplasmic reticulum stress in mice. Toxicol Lett 148: 133-139, 2004

7. Suzuki S, Tohma S, Futakawa N, Higashimoto M, Takiguchi M, Sato M : Induction of hepatic metallothionein by mitochondrial oxidative stress in mice. J Health Sci 51 : 533-537, 2005
8. Futakawa N, Kondoh M, Ueda S, Higashimoto M, Takiguchi M, Suzuki S, Sato M : Involvement of oxidative stress in the synthesis of metallothionein induced by mitochondrial inhibitors. Biol Pharm Bull 29 : 2016-2020, 2006

9. Higashimoto $M$, Isoyama N, Ishibashi S, Inoue M, Takiguchi M, Suzuki S, Ohnishi Y, Sato $\mathrm{M}$ : Tissue-dependent preventive effect of metallothionein against DNA damage in dyslipidemic mice under repeated stresses of fasting or restraint. Life Sci 84 : 569-575, 2009

10. Sato M, Ishibashi S, Higashimoto M, Kadota Y, Kawakami T, Suzuki S : Early changes induced by environmental stresses in insulin sensitivityrelated genes. Eur J Pharmacol 668 : 472-476, 2011

11. Kägi JHR, Vallee BL : Metallothionein : a cadmium- and zinc-containing protein from equine renal cortex. J Biol Chem 235 : 3460-3465, 1960

12. Nakagawa I, Suzuki M, Imura N, Naganuma A : Involvement of oxidative stress in paraquatinduced metallothionein synthesis under glutathione depletion. Free Rad Biol Med 24 : 1390-1395, 1998

13. Sato $\mathrm{M}$, Kondoh $\mathrm{M}$ : Recent studies on metallothionein : Protection against toxicity of heavy metals and oxygen free radicals. Tohoku J Exp Med 196 : 9-22, 2002

14. Shibuya K, Suzuki JS, Kito H, Naganuma A, Tohyama C, Satoh $M$ : Protective role of metallothionein in bone marrow injury caused by X-irradiation. J Toxicol Sci 33 : 479-484, 2008

15. Suzuki S, Yamamoto M, Sato M : Modulated responses to restraint stress and inflammation in metallothionein-null mice. J Health Sci 55 : 554-559, 2009

16. Thornalley PJ, Vašák $M$ : Possible role for metallothionein in protection against radiationinduced oxidative stress. Kinetics and mechanism of its reaction with superoxide and hydroxyl radicals. Biochim Biophys Acta 827 : 3644, 1985

17. Janáky R, Ogita K, Pasqualotto BA, Bains JS, Oja SS, Yoneda Y, Shaw CA : Glutathione and signal transduction in the mammalian CNS. J Neurochem 73 : 889-902, 1999

18. Min KS, Tanaka N, Horie T, Kawano H, Tetsuchikawahara N, Onosaka S: Metallothionein-enriched hepatocytes are resistant to ferric nitriloacetate toxicity during conditions of glutathione depletion. Toxicol Let 158 : 108115,2005 
19. Bowers SL, Bilbo SD, Dhabhar FS, Nelson RJ : Stressor-specific alterations in corticosterone and immune responses in mice. Brain Behav Immun $22: 105-113,2008$

20. Steiber A, Kerner J, Hoppel CL: Carnitine : a nutritional, biosynthetic, and functional perspective. Mol Aspects Med 25 : 455-473, 2004

21. Kuwajima M, Fujihara H, Sei H, Umehara A, Sei M, Tsuda TT, Sukeno A, Okamoto T, Inubushi A, Ueta Y, Doi T, Kido H : Reduced carnitine level causes death from hypoglycemia : Possible involvement of suppression of hypothalamic orexin expression during weaning period. Endocr J 54 : 911-925, 2007

22. Malaguarnera M, Vacante M, Avitabile T, Malaguarnera M, Cammalleri L, Motta M : LCarnitine supplementation reduces oxidized LDL cholesterol in patients with diabetes. Am J Clin Nutr 89 : 71-76, 2009

23. Kadowaki T, Yamauchi T, Kubota N, Hara K, Ueki K, Tobe $\mathrm{K}$ : Adiponectin and adiponectin receptors in insulin resistance, diabetes, and the metabolic syndrome. J Clin Invest 116 : 1784-1792, 2006

24. Maeda $\mathrm{K}$ : Role of adiponectin and adipocyte fatty acid binding protein in the metabolic syndrome. Diabetes Res Clin Pract 77 Suppl 1: S17-S22, 2007

25. Iwabu M, Yamauchi T, Okada-Iwabu M, Sato K, Nakagawa T, Funata M, Yamaguchi M, Namiki S, Nakayama R, Tabata M, Ogata H, Kubota N, Takamoto I, Hayashi YK, Yamauchi N, Waki H, Fukayama M, Nishino I, Tokuyama K, Ueki K, Oike Y, Ishii S, Hirose K, Shimizu T, Touhara K, Kadowaki T: Adiponectin and adipoR1 regulate $\mathrm{PGC}-1 \alpha$ and mitochondria by $\mathrm{Ca}^{2+}$ and AMPK/SIRT1. Nature 464 : 13131319, 2010

26. Bieri JG, Stoewsand GS, Briggs GM, Phillips RW, Woodard JC, Knapka JJ : Report of the American Institute of Nutrition Ad Hoc Committee on standards for nutritional studies. J Nutr 107 : 1340-1348, 1977

27. Sasaki YF, Tsuda S, Izumiyama F, Nishidate E : Detection of chemically induced DNA lesions in multiple mouse organs (liver, lung, spleen, kidney, and bone marrow) using the alkaline single cell gel electrophoresis (Comet) assay. Mutat Res 388 : 33-44, 1997

28. Collins AR: The comet assay for DNA damage and repair. Mol Biotech $26: 249-261,2004$

29. Onosaka S, Tanaka K, Doi M, Okahara K: A simplified procedure for determination of metallothionein in animal tissues. Jpn J Toxicol Environ Health 24 : 128-131, 1978

30. Meister A : Gluthathion, ascorbate, and cellular protection. Cancer Res 54 suppl : 1969s-1975s, 1994

31. Min KS : The physiological significance of metallothionein in oxidative stress. Yakugaku Zasshi $127: 695-702,2007$

32. Calandrella N, De Seta C, Scarsella G, Risuleo $\mathrm{G}$ : Carnitine reduces the lipoperoxidative damage of the membrane and apoptosis after induction of cell stress in experimental glaucoma. Cell Death Dis $1: 1-5,2010$

33. Sato M, Kawakami T, Kondoh M, Takiguchi M, Kadota Y, Himeno S, Suzuki S : Development of high-fat-diet-induced obesity in female metallothionein-null mice. FASEB J 24 : 23752384, 2010

34. Buechler C, Wanninger J, Neumeier M : Adiponectin, a key adipokine in obesity related liver diseases. World J Gastroenterol 17 : 28012811, 2011

35. Poljsak B : Strategies for reducing or preventing the generation of oxidative stress. Oxid Med Cell Longev 2011 : 1-15, 2011

36. Machlin LJ, Bendich A : Free radical tissue damage : protective role of antioxidant nutrients. FASEB J 1 : 441-445, 1987

37. Jacob RA, Burri BJ : Oxidative damage and defense. Am J Clin Nutr 63 : 985S-990S, 1996

38. Kouda K, Iki $\mathrm{M}$ : Beneficial effects of mild stress (hormetic effects) : Dietary restriction and health. J Physiol Anthropol 29 : 127-132, 2010

39. Hughes S, Samman S : The effect of zinc supplementation in humans on plasma lipids, antioxidant status and thrombogenesis. J Am Coll Nutr 25 : 285-291, 2006

40. Kelleher SL, McCormick NH, Velasquez V, Lopez V : Zinc in specialized secretory tissues : Roles in the pancreas, prostate, and mammary gland. Adv Nutr 2 : 101-111, 2011

41. Kotani M, Kim KH, Ishizaki N, Funaba M, Matsui $\mathrm{T}$ : Magnesium and calcium deficiencies additively increase zinc concentrations and metallothionein expression in the rat liver. $\mathrm{Br} \mathrm{J}$ Nutr May $9: 1-8,2012$

42. Fujimura T, Matsui T, Funaba $M$ : Regulatory responses to excess zinc ingestion in growing rats. Br J Nutr 107 : 1655-1663, 2012 